\title{
UTERINE LUTEOLYSIS IN THE RAT: EVIDENCE FOR BLOOD-BORNE AND LOCAL ACTIONS*
}

\author{
RALPH R. ANDERSON \\ Department of Dairy Husbandry, University of Missouri, \\ Columbia, Missouri, U.S.A. \\ (Received 1st September 1967)
}

\begin{abstract}
Summary. Four separate experiments were conducted on rats to determine the mechanism by which the uterus exerts its luteolytic effect upon the corpora lutea. The first experiment concerned the stimulation of immature rats by gonadotrophins to produce massive luteinization of the ovaries. Di-oestrous periods lasted 22.3 in intact and 34.0 days in completely hysterectomized rats when gonadotrophin treatment was begun at 23 days of age, and 14.9 and 32.7 days, respectively, when treatment was started at 33 days of age. Intermediate length periods occurred in animals unilaterally ovariectomized and/or unilaterally hysterectomized on the same or opposite side. In the second experiment, homotransplants of uteri into the abdominal cavities of littermates resulted in a significant reduction in the length of pseudopregnancy as compared to hysterectomized controls ( 15.5 days versus 21.5 days). In the third experiment, autotransplantation of ovaries to the uterine lumina shortened the pseudopregnancy duration significantly (11.3 versus 13.2 days). In the fourth experiment, parabiosis of littermates, in which one member of the pair was hysterectomized while the other was not, resulted in a shortened pseudopregnancy in the hysterectomized rat compared to its control ( 16.9 versus 22.1 days) but not in the intact partner (13.0 versus 13.2 days). The four experiments suggest that the uterine luteolytic mechanism involves a substance that is transported in the blood. A locally acting mechanism is also involved.
\end{abstract}

\section{INTRODUCTION}

That the uterus is concerned in determining the life span of corpora lutea has been demonstrated in pseudopregnant rats (Bradbury, 1937) and hamsters (Caldwell, Mazer \& Wright, 1967) as well as in cycling sheep (Wiltbank \& Gasida, 1956), cattle (Anderson, Neal \& Melampy, 1962), pigs (Anderson, Butcher \& Melampy, 1961) and guinea-pigs (Butcher, Chu \& Melampy, 1962a, b). Total hysterectomy results in an extension of the corpora lutea life to durations which approximate to the lengths of gestation in these species. The mechanism by which the uterus affects lysis of the corpora lutea has been

* Contribution from the Missouri Agricultural Experiment Station Journal Series No. 5219. Approved by the Director. Supported in part by grants from the U.S.P.H.S. 
shown to depend upon the quantity of viable endometrium in the organism, e.g. pig (Anderson et al., 1961), guinea-pig (Butcher et al., 1962a, b) and rat (Melampy, Anderson \& Kragt, 1964). While the evidence concerning autotransplantation of the uterus in rabbit (Sessums \& Murphy, 1933) and guineapig (Butcher et al., 1962a, b) implies that a blood-borne mechanism is involved in control of the life-span of the corpora lutea, other evidence is accumulating to suggest that a local action is involved. A complete review of this subject has been presented by Ginther (1967).

This study concerns four different experiments undertaken to clarify, to some extent, the mechanism by which the uterine endometrium causes luteal regression. The first experiment was designed to increase above normal the amount of luteal tissue in the ovaries and relate the period of di-oestrum resultant from the increase to the presence or absence of uterine tissue. Immature rats served as the model to exaggerate the conditions of normal psuedopregnancy. The second experiment involved homotransplantation of uteri to littermates. It was felt that demonstration of luteolysis resulting from a viable transplant between two different animals rather than within the same animal would lend support to the concept that a blood-borne mechanism was involved. The third experiment concerned autotransplantation of ovaries to the uterine lumina where the luteal tissue was in direct contact with the endometrium. In this case a local action and a quantitative action were considered. The fourth experiment made use of parabiotic rats to determine whether transport through the blood of a luteolytic substance from one animal to another could be demonstrated.

\section{MATERIALS AND METHODS}

Holtzman rats were kept in colony cages in a room maintained at $72 \pm 6^{\circ} \mathrm{F}$ with artificial illumination for $14 \mathrm{hr}$ of the day. An unlimited supply of commercial lab. pellets and water was provided.

\section{Experiment 1}

Immature rats were operated upon at 21 days of age and treated subcutaneously with 50 i.u. of pregnant mare serum gonadotrophin (PMSG, Ayerst Equinex) at either 23 or 33 days of age and 25 i.u. of human chorionic gonadotropin (HCG, Ayerst A.P.L.) $60 \mathrm{hr}$ afterwards. Immature rats were used in order to have a model in which the luteal tissue was much greater than it normally would be in relation to the uterine tissue present.

Groups were treated at the two different ages to test the hypothesis that the luteolytic capacity of the uterus was developing between 20 and 40 days of age in the rat. Vaginal smears were made daily by water lavage beginning on the day of HCG injection, which was designated Day 0, and ended when a complete cycle of normal length followed the period of di-oestrum (pseudopregnancy). The first day that a positive pro-oestrum smear was detected served to measure the last day of the pseudopregnant period.

Operations involving hysterectomy and/or ovariectomy were performed by ventral midline incisions under ether anaesthesia when the animals were 21 
days old. Two exceptions were groups totally ovariectomized at 30 days of age (Day 5 of di-oestrum) or at 40 days of age (Day 5 of di-oestrum when PMSG was given at 33 days of age).

Experiment $1 A$. Seven groups of ten rats each were injected with PMSG on Day 23. Surgical operations were performed in Groups 3 to 6 on Day 21. Groups were as follows:

Group 1-normal control rats

Group 2-unilateral ovariectomy (Day 5 of di-oestrum or 30 days of age)

Group 3-total hysterectomy

Group 4-unilateral hysterectomy

Group 5-unilateral hysterectomy and ovariectomy ipsilaterally

Group 6-unilateral hysterectomy and ovariectomy contralaterally

Group 7-total hysterectomy (Day 5 of di-oestrum or 30 days of age)

Experiment $1 B$. Five groups of ten rats each were injected with PMSG on Day 33. Surgical operations were performed in Groups 3 and 4 on Day 21. These groups were as follows:

Group 1-normal control rats

Group 2-unilateral ovariectomy (Day 5 of di-oestrum or 40 days of age)

Group 3-unilateral hysterectomy and ovariectomy ipsilaterally

Group 4-unilateral hysterectomy and ovariectomy contralaterally

Group 5-total hysterectomy (Day 5 of di-oestrum or 40 days of age)

Animals were killed after one complete cycle following the termination of pseudopregnancy and were examined for accuracy of tissue removal. The data were analysed by Duncan's multiple range test (1955).

\section{Experiment 2}

This was designed to test the effect of homotransplanted uteri on the length of pseudopregnancy. Female littermates were paired and reared until they had had several normal cycles as indicated by vaginal smears. At this time they weighed over $130 \mathrm{~g}$ and were over 60 days of age. One member of each pair was then rendered pseudopregnant by cervical stimulation with a glass rod ( $\mathrm{DeFeo}$, 1963), while the second member was observed through a further oestrous cycle. Both littermates were hysterectomized when the pseudopregnant member was 4 to 7 days post coitus and its pair-mate was in oestrus. The uterus of the oestrous rat was transplanted to the pseudopregnant member and the uterus from the pseudopregnant rat was transferred to the oestrous rat. The transplanted uterus was placed in a site near the spleen of the recipient animal since preliminary work had indicated that this area was more favourable for uterine transplantation than other areas. Vaginal smears were continued in all animals until oestrous cycles were re-established. The viability of the uterine grafts was determined by gross observations at autopsy following completion of a normal oestrous cycle and by histological evidence of uterine epithelial cells in sections of $10 \mu$ thickness stained with haematoxylin and eosin. The data were analysed by Student's $t$-test. 


\section{Experiment 3}

Autotransplantation of the ovaries into the uterine lumina was performed in sixty-two mature rats subsequent to the establishment of normal oestrous cycling patterns. After two normal cycles, the ovaries were transplanted into the corresponding uterine horns on the day of oestrus during the third cycle. The operation was performed during oestrus because the uterus was flexible enough to receive the ovary at this time and at no other time of the cycle. Two additional oestrous cycles were followed after the operation, before the animal was rendered pseudopregnant by a glass rod. Those which did not cycle within 2 weeks were autopsied and the ovaries were inspected under a dissecting microscope; those which cycled were not autopsied before completion of a normal cycle following the end of pseudopregnancy.

\section{Experiment 4}

The effect of parabiosis on the length of pseudopregnancy was studied. Fourteen normal and twenty hysterectomized rats were not parabiosed but served to establish control values for pseudopregnancy durations (Groups A and $B$, respectively). Thirty-four pairs of littermates were followed through several normal cycles. The animals were divided into groups and treated as follows:

Groups $\mathrm{C}$ and $\mathrm{D}$ were parabiosed when one pairmate was in di-oestrus of a normal cycle (Group C) and the other was induced into pseudopregnancy 5 or 6 days earlier (Group D).

Groups $\mathrm{E}$ and $\mathrm{F}$ were parabiosed when each member of the pair was pseudopregnant 4 to 6 days. One member had an intact uterus (Group E) while the other was hysterectomized before induction of pseudopregnancy (Group F).

Groups $\mathrm{G}$ and $\mathrm{H}$ were parabiosed before induction of pseudopregnancy. One member of the pair (Group G) was totally hysterectomized several cycles before parabiosis. The second member had an intact uterus. When normal oestrous cycles were established following parabiosis, each member of the pair was made pseudopregnant by using a glass rod. All parabioses were carried out according to Bunster \& Meyer (1933). The data were analysed by Kramer's multiple range test (1956).

\section{Experiment $1 A$}

\section{RESULTS}

Immature rats injected with PMSG at 23 days of age and HGG $60 \mathrm{hr}$ later had di-oestrous periods (pseudopregnancies) of $22 \cdot 3 \pm 0 \cdot 7$ days duration (Table 1 ). This may be compared to the normal length of $13 \cdot 2 \pm 0.5$ days pseudopregnancy experienced in mature female rats of this strain $(P<0.01)$. Unilateral ovariectomy 5 days after HGG treatment resulted in a di-oestrous period of $17 \cdot 6 \pm 1.5$ days which was significantly lower than 22.3 days and higher than 13.2 days $(P<0.05)$. Total hysterectomy performed at 21 or 30 days of age resulted in pseudopregnancies of 31.3 or 34.0 days, respectively. Animals with one uterine horn removed had pseudopregnancies of 28.4 days, approximately midway between the control and the totally hysterectomized group. Animals with one 

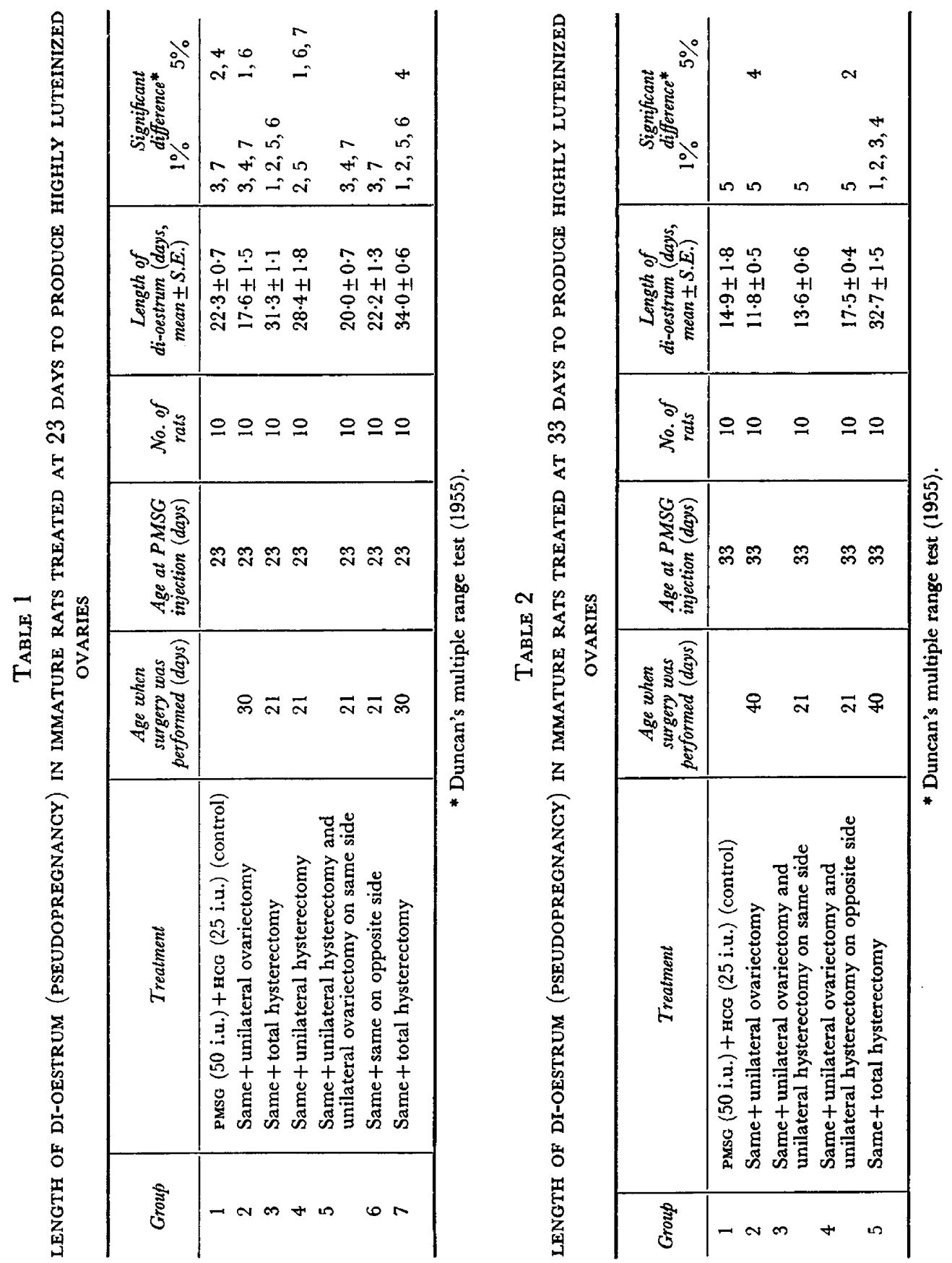
uterine horn and one ovary removed ipsilaterally or contralaterally had di-oestrual periods averaging 20.0 and 22.2 days, respectively. These are not significantly different from the control.

\section{Experiment $1 B$}

Rats injected with PMSG at 33 days of age and HCG $60 \mathrm{hr}$ later had pseudopregnancies of 14.9 days, significantly less than the 22.3 days found in younger rats $(P<0.01)$ but not different from the pseudopregnancy duration of normal mature rats (13.2 days). Unilateral ovariectomy 5 days after HGG treatment resulted in a slight non-significant reduction in the length of pseudopregnancy (Table 2). Unilateral ovariectomy and hysterectomy performed ipsilaterally or contralaterally resulted in pseudopregnancy durations of 13.6 and 17.5 days, respectively (non-significant differences).

Total hysterectomy of rats on Day 5 of di-oestrum (40 days of age) resulted in pseudopregnancies averaging 32.7 days (Group 5 of Table 2). This duration was significantly longer than other groups given PMSG and HCG at the same age and was similar to the di-oestrum observed in hysterectomized rats treated 10 days earlier with PMSG and HGG.

\section{Experiment 2}

Viable homotransplanted uteri were found in only twelve out of forty-six rats (twenty-three littermate pairs) at laparotomy/autopsy upon completion of one normal oestrous cycle beyond pseudopregnancy. The twelve successful uterine transplants occurred when uteri, obtained from donor rats in oestrus, were placed in the peritoneal cavity of pseudopregnant recipient rats. Viability of the transplants was verified by gross and microscopic inspection after autopsy. The mean length of pseudopregnancy in those animals in which the homotransplants had survived was $15 \cdot 5 \pm 0.8$ days, while pseudopregnancy in the group of thirty-four rats with necrotic uterine transplants was $21.5 \pm 0.5$ days. Thus the presence of viable uterine tissue in the peritoneal cavity of hysterectomized pseudopregnant rats resulted in a highly significant shortening of the duration of pseudopregnancy as compared with that in hysterectomized rats with necrotic uterine transplants $(P<0.01$ using Student's $t$-test $)$.

\section{Experiment 3}

Autotransplantation of ovaries into the uterine lumina was successful in thirty-seven of sixty-two rats. Viability of the ovaries was determined first by the oestrous cycling and later by the condition of the transplanted ovaries at autopsy. Gross observation of the transplant was sufficient to evaluate viability. Those animals which failed to show normal cycles following the transplantation were autopsied after 2 weeks and were found to have necrotic ovarian transplants in all cases (twenty-five rats). Each of the thirty-seven animals, which cycled and subsequently were made pseudopregnant, had viable ovaries upon autopsy. Autotransplantation of ovaries into the uterine lumina resulted in a pseudopregnancy duration of $11.3 \pm 0.4$ days in the thirty-seven rats, significantly less than the $13.2 \pm 0.5$ days in the normal control group $(P<0.05$ by Student's $t$-test). 


\section{Experiment 4}

Parabiosis in fourteen pairs of siblings indicated that one member of the pair would continue to cycle normally while the other member experienced a pseudopregnancy of slightly less than normal duration (Table 3 ). When a hysterectomized pseudopregnant rat was placed in parabiosis with a normal pseudopregnant rat on Days 4 to 6 after cervical stimulation to initiate pseudopregnancy, the length of pseudopregnancy in the normal member of the pair was unchanged while that in the hysterectomized partner was shortened

TABLE 3

EFFEGT OF HYSTERECTOMY AND PARABIOSIS ON PSEUDOPREGNANGY DURATION IN THE RAT

\begin{tabular}{|c|c|c|c|c|c|}
\hline Group & Treatment & $\begin{array}{l}\text { No. } \\
\text { of } \\
\text { rats }\end{array}$ & $\begin{array}{c}\text { Duration of } \\
\text { pseudopregnancy } \\
(\text { days, mean } \pm S . E .)\end{array}$ & $\begin{array}{l}\text { Significant } \\
\text { difference, } \\
\text { probability } \\
1 \%\end{array}$ & $y^{*} \%$ \\
\hline $\begin{array}{l}\mathbf{A} \\
\mathbf{B}\end{array}$ & $\begin{array}{l}\text { Intact pseudopregnant } \\
\text { Hysterectomized pseudopregnant }\end{array}$ & $\begin{array}{l}14 \\
20\end{array}$ & $\begin{array}{l}13 \cdot 2 \pm 0 \cdot 5 \\
22 \cdot 1 \pm 0 \cdot 8\end{array}$ & $\begin{array}{l}\text { B } \\
\text { A }\end{array}$ & \\
\hline $\begin{array}{l}\text { C } \\
\text { D }\end{array}$ & $\begin{array}{l}\text { Parabiosis } \\
\text { Intact cycling } \\
\text { Intact pseudopregnant }\end{array} \quad \begin{array}{l}\text { Joined after } \\
\text { pseudopregnant }\end{array}$ & $\begin{array}{l}14 \\
14\end{array}$ & $\begin{array}{c}\text { 4- to } 6 \text {-day cycles } \\
12 \cdot 8 \pm 0 \cdot 6\end{array}$ & B, E & \\
\hline $\mathbf{E}$ & 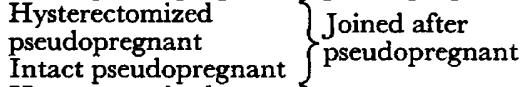 & $\begin{array}{l}10 \\
10\end{array}$ & $\begin{array}{l}17 \cdot 8 \pm 0.9 \\
13 \cdot 8 \pm 0.5\end{array}$ & $\underset{\mathrm{B}, \mathrm{E}}{\mathrm{A}, \mathrm{B}}$ & $\mathbf{H}$ \\
\hline $\begin{array}{l}\mathbf{G} \\
\mathbf{H}\end{array}$ & $\left.\begin{array}{l}\text { Hysterectomized } \\
\text { pseudopregnant } \\
\text { Intact pseudopregnant }\end{array}\right\}$ Joined before & $\begin{array}{l}10 \\
10\end{array}$ & $\begin{array}{l}16.0 \pm 0.8 \\
12 \cdot 2 \pm 0.7\end{array}$ & $\begin{array}{l}\text { B } \\
\text { B }\end{array}$ & $\underset{\mathrm{G}}{\mathrm{A}, \mathrm{H}}$ \\
\hline
\end{tabular}

* Kramer's multiple range test (1956).

significantly from that of the hysterectomized pseudopregnant control group $(17 \cdot 8 \pm 0 \cdot 9$ days versus $22 \cdot 1 \pm 0 \cdot 8$ days). Initiation of the parabiosis several oestrous cycles before induction of pseudopregnancy resulted in a shortened duration of pseudopregnancy for both members of the pair. The hysterectomized partner experienced a pseudopregnancy of significantly shorter length than its control $(16 \cdot 0 \pm 0.8$ days versus $22 \cdot 1 \pm 0 \cdot 8$ days for the control, $P<0 \cdot 01)$ while the normal pseudopregnant member did not $(12 \cdot 2 \pm 0 \cdot 7$ days versus $13 \cdot 2 \pm 0.5$ days, not significant).

\section{DISCUSSION}

Hysterectomy was found to increase the life span of the corpora lutea of pseudopregnancy from 13.2 days to 22.1 days in mature rats. Treatment of immature rats with gonadotrophins was undertaken in an effort to increase luteal tissue of the ovary above the amount present in normal pseudopregnancy. This manipulation was considered to be the basis of an experimental model in which amounts of luteal tissue were increased in relation to uterine tissue. To carry this relationship to the extreme, immature rats were used. It was reasoned that uterine luteolysis is characteristic of organ maturation just as gonadotrophin secretion in the pituitary gland depends upon maturation processes. An effort was made to determine the age at which the rat acquires the uterine luteolytic activity. Results of the present study suggest that luteolysis 
was occurring in rats 26 to 48 days of age as evidenced by di-oestrous periods of 22.3 in intact and 31.3 or 34.0 days in hysterectomized rats treated similarly with PMSG and HCG. However, when the treatment of PMSG and HCG was delayed for 10 days the uterine luteolytic activity appeared to be much more highly developed as indicated by di-oestrous periods of 14.9 days in intact and 32.7 days in hysterectomized rats. The fact that periods of di-oestrum were as long as 34 days after hysterectomy in immature rats treated with PMSG and HCG would lead one to suggest that this animal might be an ideal tool for assays involving luteolytic substances.

Subtotal hysterectomy resulted in lengthened pseudopregnancy durations when compared to controls, and unilateral ovariectomy resulted in a shortened di-oestrous period compared to its control. These findings support the results of studies which have shown that a quantitative relationship exists between the amount of uterine tissue removed and the length of the di-oestrous interval.

Homotransplantation of uterine tissue has met with limited success because of the rejection by an organism of protein from a source that is foreign to it. However, Caldwell et al. (1967) have circumvented this problem by using the cheek pouch of the hamster to accept transplants of uterine endometrium from other individuals of the same and of different species. Just as their evidence suggests a blood-borne mechanism in uterine luteolysis, the present experiment, using siblings to demonstrate successful homotransplantation of the uterus, implicates a substance transported in the blood as being primary in the uterine control of luteal regression.

The technique of autotransplanting ovaries to the uterine lumina has been used in rabbits (Suzuki, Akiyama \& Fukushima, 1962) but not in rats. In the present study it was performed with a reasonable degree of success. The results of the experiment may be interpreted as evidence for a local action or as a concentration of the blood-borne luteolytic phenomenon. A significant point to emphasize at this time is that a local effect of uterine luteolysis depends upon the maintenance of the integrity of the oviduct and mesosalpinx in relation to the uterus and ovary (Barley, Butcher \& Inskeep, 1966). Such a relationship was destroyed in this experiment and, therefore, the interpretation of the present results may be in favour of a blood-borne mechanism.

A locally operating mechanism has been suggested as the mediator of uterine luteolysis in the rat (Barley et al., 1966). Such a mechanism is not ruled out completely by the present investigation because removal of the uterine horn and the ipsilateral ovary resulted in pseudopregnancy durations that were shorter by several days than the groups having had the operations performed contralaterally. Since no significant differences were found, the data may mean that the blood-borne mechanism of control of corpora lutea life-span by the uterus is more important than a local control.

Uterine control of luteal regression may be mediated through the nervous system (Hill \& Alpert, 1961) or it may be by way of a luteolytic hormone secreted by the endometrium which acts directly upon the corpora lutea (Williams, Johnston, Lauterbach \& Fagan, 1967). Other possibilities are that hysterectomy results in an oestrogen-sparing effect (Heckel, 1942) or a progesterone-sparing effect (de Jongh \& Wolthuis, 1964). 
Parabiosis has been used by several investigators for reproduction studies (Zacherl, 1927; Kiracofe \& Spies, 1966; Butcher, 1966). In the present study the shortening of pseudopregnancy in the hysterectomized pair-mate of rats in parabiosis with each other was thought to be due to the transfer through the blood of a luteolytic factor originating from the partner having an intact non-gravid uterus. The possibility that the uterus may inactivate a substance from the hysterectomized pair-mate by a metabolic process cannot be discounted. In any case, the experiment suggests that the mechanism of uterine luteolysis involves a blood-borne substance.

When the four experiments are considered together, the evidence favours a blood-borne mechanism as being of primary importance in uterine luteolysis and a locally acting mechanism as being of secondary importance.

\section{REFERENCES}

Anderson, L. L., Butcher, R. L. \& Melampy, R. M. (1961) Subtotal hysterectomy and ovarian function in gilts. Endocrinology, 69, 571.

Anderson, L. L., NeAl, F. C. \& Melampy, R. M. (1962) Hysterectomy and ovarian function in beef heifers. Am. F. vet. Res. 23, 794.

BARLey, D. A., Butcher, R. L. \& INSKeEP, E. K. (1966) Local nature of utero-ovarian relationships in the pseudopregnant rat. Endocrinology, 79, 119.

Bradbury, James T. (1937) Prolongation of the life of the corpus luteum by hysterectomy in the rat. Anat. Rec. (Suppl.), 70, 51.

Bunster, E. \& Meyer, R. K. (1933) An improved method of parabiosis. Anat. Rec. 57, 339.

Butcher, R. L. (1966) Factors affecting luteal regression following parabiosis in the rat. Endocrinolog', 79, 457.

Butcher, R. L., Ghu, K. Y. \& Melampy, R. M. (1962a) Effect of uterine autotransplants on the estrous cycle in the guinea pig. Endocrinology, 70, 442 .

Butcher, R. L., Ghu, K. Y. \& Melampy, R. M. (1962b) Utero-ovarian relationships in the guinea pig. Endocrinology, 71, 810.

Caldwell, B. V., Mazer, R. S. \& WRight, P. A. (1967) Luteolysis as affected by uterine transplantation in the Syrian hamster. Endocrinology, 80, 477.

DeFeo, V. J. (1963) Temporal aspect of uterine sensitivity in the pseudopregnant or pregnant rat. Endocrinology, 72, 305.

DE Jongh, S. E. \& Wolthuis, O. L. (1964) Factors determining cessation of corpus luteum function; the possible role of oestradiol and progesterone. Acta endocr., Copenh. Suppl. 90, 125.

Duncan, D. B. (1955) New multiple range and multiple F test. Biometrics, 11, 1.

Ginther, O. J. (1967) Local utero-ovarian relationships. 7. Anim. Sci. 26, 578.

HeCKeL, G. P. (1942) The estrogen sparing effect of hysterectomy. Surgery Gynec. Obstet. 75, 379.

HiLl, R. T. \& ALPERT, M. (1961) The corpus luteum and the sacral parasympathetics. Endocrinology, $69,1105$.

KirAcofe, G. H. \& SPIEs, H. G. (1966) Effect of parabiosis or uterine extracts on pseudopregnancy in hysterectomized rats. 7. Reprod. Fert. 12, 217.

KRAMER, G. Y. (1956) Extension of multiple range test to group means with unequal numbers of replications. Biometrics, 12, 307.

Melampy, R. M., Anderson, L. L. \& Kragt, G. L. (1964) Uterus and life span of rat corpora lutea. Endocrinology, 74, 501.

Sessums, J. V. \& MuRPhy, D. (1933) The influence of the endometrium upon the rabbit ovary after hysterectomy. Surgery Gynec. Obstet. 56, 600.

Suzuri, M., Akryama, S. \& Fukushima, M. (1962) Ovarian transplantation for the treatment of gonadal anomalies. Tohoku F. exp. Med. 76, 53 .

Wilitams, W. F., Johnston, J. O., Lauterbach, M. \& Fagan, B. (1967) Luteolytic effect of a bovine uterine powder on the corpora lutea, follicular development and progesterone synthesis of the pseudopregnant rabbit ovary. 7. Dairy Sci. 50, 555.

Wiltbank, J. N. \& Casida, L. E. (1956) Alteration of ovarian activity by hysterectomy. F. Anim. Sci. $15,134$.

Zacherd, H. (1927) Über das Verhalten der Brunst bei der Parabiose der Ratter. Klin. Wschr. 6, 16. 